\title{
Examining the Effect of the Die Angle on Tool Load and Wear in the Extrusion Process
}

Irena Nowotyńska and Stanisław Kut

(Submitted April 23, 2013; in revised form October 12, 2013; published online January 29, 2014)

\begin{abstract}
The tool durability is a crucial factor in each manufacturing process, and this also includes the extrusion process. Striving to achieve the higher product quality should be accompanied by a long-term tool life and production cost reduction. This article presents the comparative research of load and wear of die at various angles of working cone during the concurrent extrusion. The numerical calculations of a tool load during the concurrent extrusion were performed using the MSC MARC software using the finite element method (FEM). Archard model was used to determine and compare die wear. This model was implemented in the software using the FEM. The examined tool deformations and stress distribution were determined based on the performed analyses. The die wear depth at various working cone angles was determined. Properly shaped die has an effect on the extruded material properties, but also controls loads, elastic deformation, and the tool life.
\end{abstract}

Keywords die angle, extrusion process, numerical simulation, tool load, wear

\section{Introduction}

Recently, the industry strives not only to improve the dimensional accuracy and surface quality of produced goods, but also on reducing the manufacturing costs. Due to several advantages related to the extrusion process, i.e., high reduction degree in a single operation, very good dimensional tolerance and surface quality of goods, good mechanical properties, no need to use the thermal processing, the extrusion process becomes competitive to other manufacturing methods. The extrusion process is characterized by several parameters: stock geometry, tool (die) shape, forming order, friction, properties of extruded material and tools (Ref 1).

Besides of achieving a required product shape, in this technology it is necessary to account for an economically justified tool life. The tool (die) life is limited by two factors: the wear, which has an affect on the product's dimensional tolerance, and the fatigue, which causes unexpected and sudden fracture. In order to achieve the effective forming, the die shape must be optimally specified in the product design stage. In the real life it is very difficult to prevent the defects caused by die wear and local concentration of stress in the die, which depend on several process parameters (Ref 2). When determining the tool durability we account for the tribological wear, which causes the structural changes and properties of the top contact layers. Moreover, the friction causes the heterogeneous state of stress and uneven deformation in the volume of plastically

Irena Nowotyńska and Stanisław Kut, Rzeszow University of Technology, al. Powstancow Warszawy 12, 35-959 Rzeszow, Poland. Contact e-mail: i_nowot@prz.edu.pl.

formed material, which in turn results in increase of deformation force, increase of tool wear. All these factors have a negative impact on the product surface.

Recently performed several researches, both experimental and numerical, contributed to a development of better tool designing methods. Most of these researches was related to the wear, mainly the wear model and its predictability and capability to reduce the wear speed. The first attempt to determine the relation between the wear and material mechanical properties was made by Tonn in 1937, who presented the empirical abrasive wear's equation (Ref 3). In 1940, Holm calculated the amount of substances used in relation to the unitary slip patch. The general wear model presented by Archard was used to predict the die wear (Ref 4). According to this model, the wear amount is directly proportional to the wear coefficient between the die and the workpiece, the die surface pressure, relative friction path length between the die and the workpiece and inversely proportional to the die material hardness. Demirci et al. (Ref 5) investigated the wear behavior of hot extruded Al-Si and Al-Mg alloys under dry conditions. Die cast Al-Mg alloy containing $1.7 \% \mathrm{Mg}$ and Al-Si alloy containing $3.3 \% \mathrm{Si}$ were extruded at 1.6 and 2 ratios. The wear test results revealed that the extrusion ratio had an influence on the wear rate and that the samples extruded at a ratio of $1.6 \mathrm{had}$ a lower wear resistance than the ones extruded at a ratio of 2 . Choi et al. (Ref 6) developed a methodology for estimating abrasive die wear and plastic deformation in a warm forging operation, using a tempering parameter. The predictions have been compared with experimental results and it was concluded that this method can be used for estimation of die failure (wear and plastic deformation) in hot/warm forging.

Sobis et al. and others (Ref 7,8$)$ estimated the die wear during hot forging using the finite element method (FEM). Sobis et al. examined actual contact areas to forecast the wear, which is within the limits specified in Archard model (Ref 7). The researchers examined the friction mechanism in the metal forming processes (Ref 9). Painter et al. (Ref 10) analyzed the die wear during hot extrusion using the FEM and the DEFORM 
and WEAR software, which enables forecasting the wear conditions. Behrens (Ref 11) suggested an advanced model in order to assess the influence of sliding velocity on the wear in relation to the influence of the contact normal pressure between workpiece and tool.

Lee and Im (Ref 2) also used the FEM in order to examine the wear and elastic deformation of die. Kang et al. (Ref 12, 13) proposed the new wear model, considering the thermal softening and used it to calculate the wear profile of a rotor pole for a car manufactured using the hot forging process. Iwama and Morimoto (Ref 14) examined the temperature rise caused by friction and also checked the effect of lubrication conditions on the die wear and life. The authors (Ref 15) by using numerical simulations determined the size of the die during the extrusion of various non-ferrous metals. Altan and Knoerr (Ref 16) performed the analysis using the FEM with the DEFORM software in order to research the material flow, temperature, deformation, and stress to achieve more effective die and process design. It appeared that the stress concentration in dies was directly related to its life. It also determined that the die life may be improved by stress relieving due to die geometry change.

As previously mentioned, the tool life is influenced by multiple factors, including the angle of the die working cone. The examinations performed with unconventional dies, i.e., convex dies with the working cone angle higher than $90^{\circ}$, stated that these dies provide with more advantageous material flow in the main deformation zone (Ref 17, 18). With convex dies of the working cone angle $\alpha=93^{\circ}$ the flawless product may be achieved (Ref 19). Thus, it is justified to perform researches related to the effect of the die angle on its life.

The main purpose of this article is to analyze the effect of the die angle on the elastic deformation and the tool wear during the extrusion process.

\section{Experimental Researches}

Before the numerical analysis of the tool life in the extrusion process, the experimental researches were performed in order to validate the developed numerical model. The experimental researches were performed on the test stand, which included the vertical press equipped with the recording device for the extrusion force and the punch displacement (Fig. 1). The flat die made of $\mathrm{NC} 10$ steel was used in the experimental extrusion process. The hardness of the surface of the die was $530 \mathrm{HV}$. Table 1 summarizes the basic die parameters in the researches, which were presented on the diagram on Fig. 2. The hard lead was used as a research material. Some properties of materials used in researches were presented in Table 2.

The specimens used in the experimental researches were cylinders of diameter $32 \mathrm{~mm}$ and height $72 \mathrm{~mm}$. The extrusion process was conducted until about half of the billet length was extruded. Such an amount of extruded material enabled achieving of steady flow state. The test equipped with the computerized measurement system enabled to determine the change of the extrusion force versus punch displacement. The resulting force characteristics was used further to validate the numerical model. The improvement of the FEM model convergence in successive simulations was achieved by modifying the calculation parameters, as: the mesh size, global remeshing type and criteria, computation step size, etc. Finally,

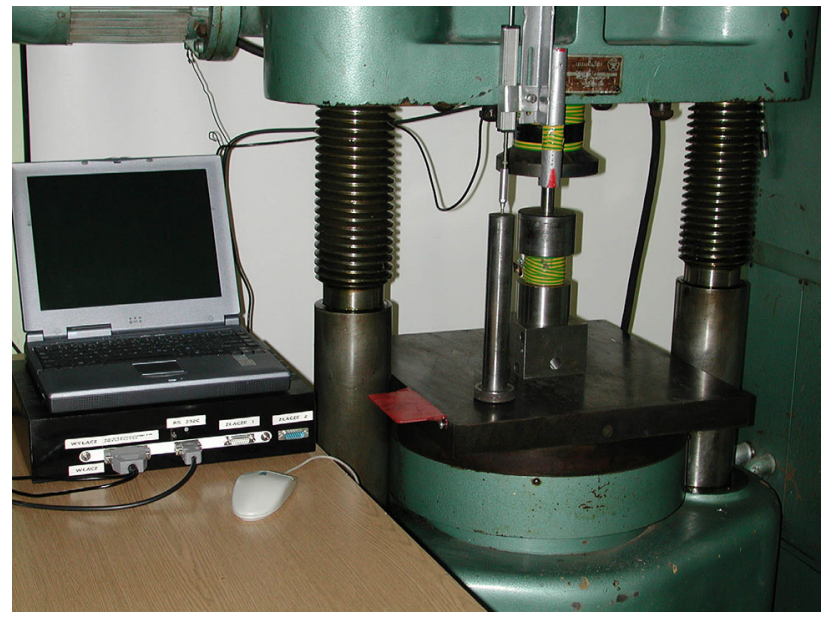

Fig. 1 Experimental stand for the extrusion process

Table 1 Basic dimensions of dies used in the extrusion

\begin{tabular}{ll}
\hline Parameter & Value \\
\hline Working angle of the die cone $\alpha,{ }^{\circ}$ & $90,95,105$ \\
Die diameter $D_{\mathrm{M}}, \mathrm{mm}$ & 36 \\
Die height $H_{\mathrm{M}}, \mathrm{mm}$ & 20 \\
Die hole diameter $D_{\mathrm{O}}, \mathrm{mm}$ & 20.78 \\
Bearing length $l_{\mathrm{k}}, \mathrm{mm}$ & 2 \\
\hline
\end{tabular}

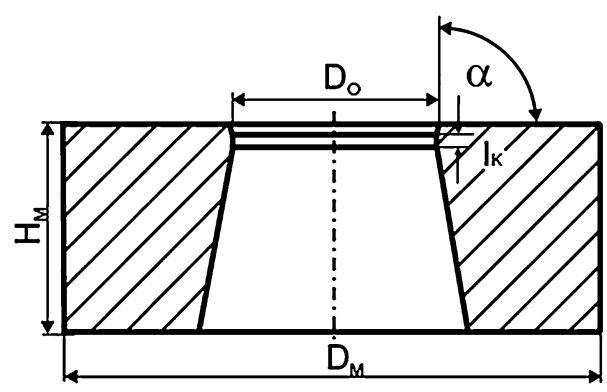

Fig. 2 The diagram of longitudinal cross-section of the die (see Table 1)

Table 2 Some features of materials used in investigations

\begin{tabular}{lccc}
\hline Material & $\begin{array}{c}\text { Chemical } \\
\text { composition, wt.\% }\end{array}$ & $\begin{array}{c}\boldsymbol{R}_{\mathbf{e}} \text {, Yield } \\
\text { stress, } \\
\text { MPa }\end{array}$ & $\begin{array}{c}\text { Brinell } \\
\text { hardness HB }\end{array}$ \\
\hline Hard lead OT3 & $\begin{array}{c}2.5-3.5 \mathrm{Sb} ; 0.015 \mathrm{As} ; \\
0.04 \mathrm{Cu} ; 0.012 \mathrm{Fe} ; 0.01 \mathrm{Bi}\end{array}$ & 10 & 8.7 \\
\hline
\end{tabular}

the model that was the most converged to the experiment (Fig. 3) was taken for the research purposes.

The model which was based on the experimental data, was used to perform the thorough theoretical analysis of the problem with more parameters, and this enabled to determine the effect of the tool geometry on the load and wear of examined dies. 


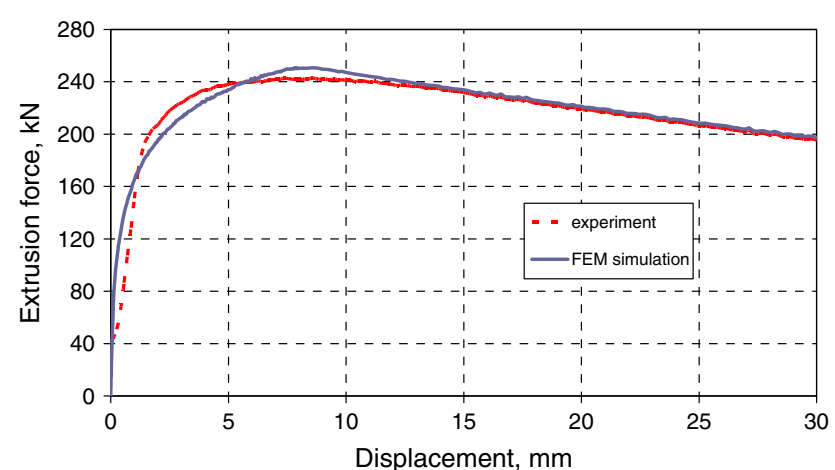

Fig. 3 Experimental and numerical force characteristic of extrusion process

\section{Numerical Analysis}

The numerical modeling of the concurrent extrusion process was performed using the MSC MARC/Mentat software supporting the nonlinear contact problems. The geometrical model of the extrusion process was developed based on the experimental model. The numerical modeling was performed for dies with working cone angle of $\alpha=\left(90^{\circ}, 95^{\circ}\right.$, and $\left.105^{\circ}\right)$. This enabled to determine the effect of die working cone angle on the die wear and elastic deformation.

The developed model is two-dimensional (a flat model), which was analyzed by applying the axis-symmetric state of stress. The example geometry of the developed model with the contact conditions and the element mesh for deformed body is presented in Fig. 4. It was assumed that the punch and container surfaces were ideally rigid. The mechanical properties of the die being deformed in the elastic range are as follows: $E=210000 \mathrm{MPa}$ and $v=0.3$. Whereas the extruded material properties were described by applying the rigid elastic body model with nonlinear strain hardening. The strain hardening curve course for extruded material was depicted with the Hollomon's equation as below:

$\sigma_{\mathrm{pl}}=K \varphi_{i}^{n}$

The material constants for hard lead were $K=40 \mathrm{MPa}$, $n=0.23$. The friction model was depicted using the Coulomb law. The friction coefficients were: between the extruded material and tools and container $\mu=0.25$, between deformable die and container $\mu=0.1$. Tool hardness $H$ in Eq (3) was the same as in the experiment. In order to create FEM grid of deformable body Class 4 Type 10 elements were used-planestrain quadrilateral (Ref 20). The numerical simulation was performed using the global remeshing function.

\subsection{The Comparison Analysis of Load and Deformation of Elastic Tools}

In the extrusion process, the die replacement is mainly caused by two factors: the die wear resulting in the extruded product surface quality deterioration or the sudden facture due to, e.g., material fatigue. The wear amount depends on many parameters, as a normal stress, extruded material length, temperature, whereas the fatigue fracture exists usually in areas of high stress concentration, which may be caused by improper surface finishing or batch positioning errors. Thus, it is important to determine the effect of tool geometry on its load and the elastic deformation.

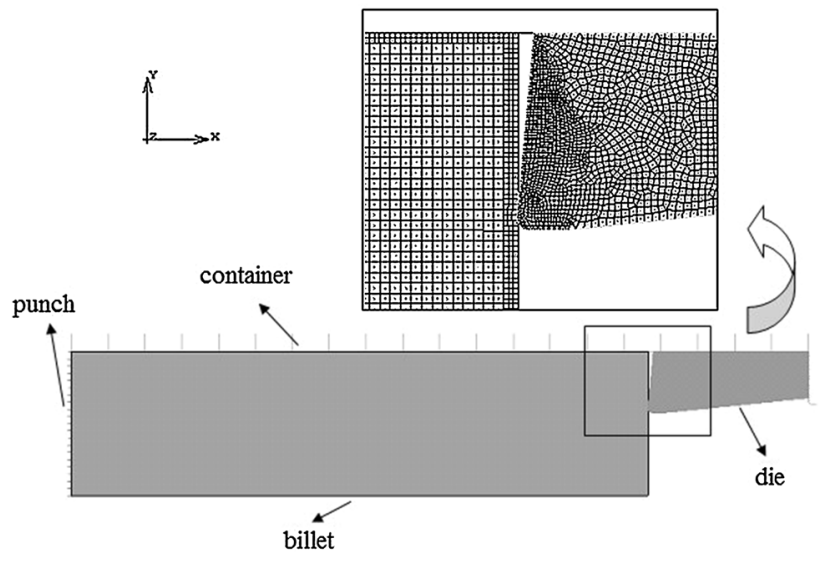

Fig. 4 Two-dimensional geometrical model of the FEM simulation of extrusion process

The stress distribution and the elastic deformation of tool when extruding with three angles of the die working cone was presented in this article. According to the results, the stress distribution in the die (Fig. 5, 6) depends on used angle $\alpha$. When using the flat die, the most loaded part of a die is the one near the calibrating strip and the one where the equivalent stress (Fig. 5a) equals $160 \mathrm{MPa}$. Once the die angle is increased up to $95^{\circ}$, the highest stress is concentrated near the die hole and become to appear simultaneously along the internal die surface. Using the die with working cone angle of $105^{\circ}$ a slight area of large stress starts appearing in the die hole area. In turn, the convex die specific radial stress (Fig. 5b) revealed may indicate a different metal flow by the die comparing to the flat die. When analyzing the peripheral stress distribution (Fig. 6), the highest stress values exist for the convex die with the working cone angle of $105^{\circ}$.

When analyzing the die apex displacement caused by the load, it can state that the convex die with working cone angle of $\alpha=95^{\circ}$ had the highest displacement in the axial direction $(X$ axis). Whereas the lowest die apex displacement was observed for the convex die with $\alpha=105^{\circ}$ (Fig. 7a). The displacement values in the radial direction ( $Y$ axis) have different values. In this case, the highest displacement values were observed for the convex die with the working cone angle of $\alpha=105^{\circ}$ (Fig. 7b).

The performed stress distribution and die edge apex displacement course analysis allow to determine the level and the place of the stress concentration. Properly shaped die has an effect not only on the extruded material properties, but also controls the tool load. The way of researching presented in this article, which includes the tool wear and die stress concentration and deformation analysis, may be helpful on the die designing stage, as this provides with important data affecting the die damage.

\subsection{Comparative Analysis of Tool Wear}

The wear damages the mating surfaces. The wear level depends on many parameters, as temperature, surface roughness, relative material slip speed on the tool, pressure, length of sliding surfaces, and lubrication. Due to its complexity, it is very difficult to determine relations between parameters and the wear in the metal forming processes, which may be characterized by very high contact pressure between die and workpieces. Thus, the wear must be researched in detailed in order to 

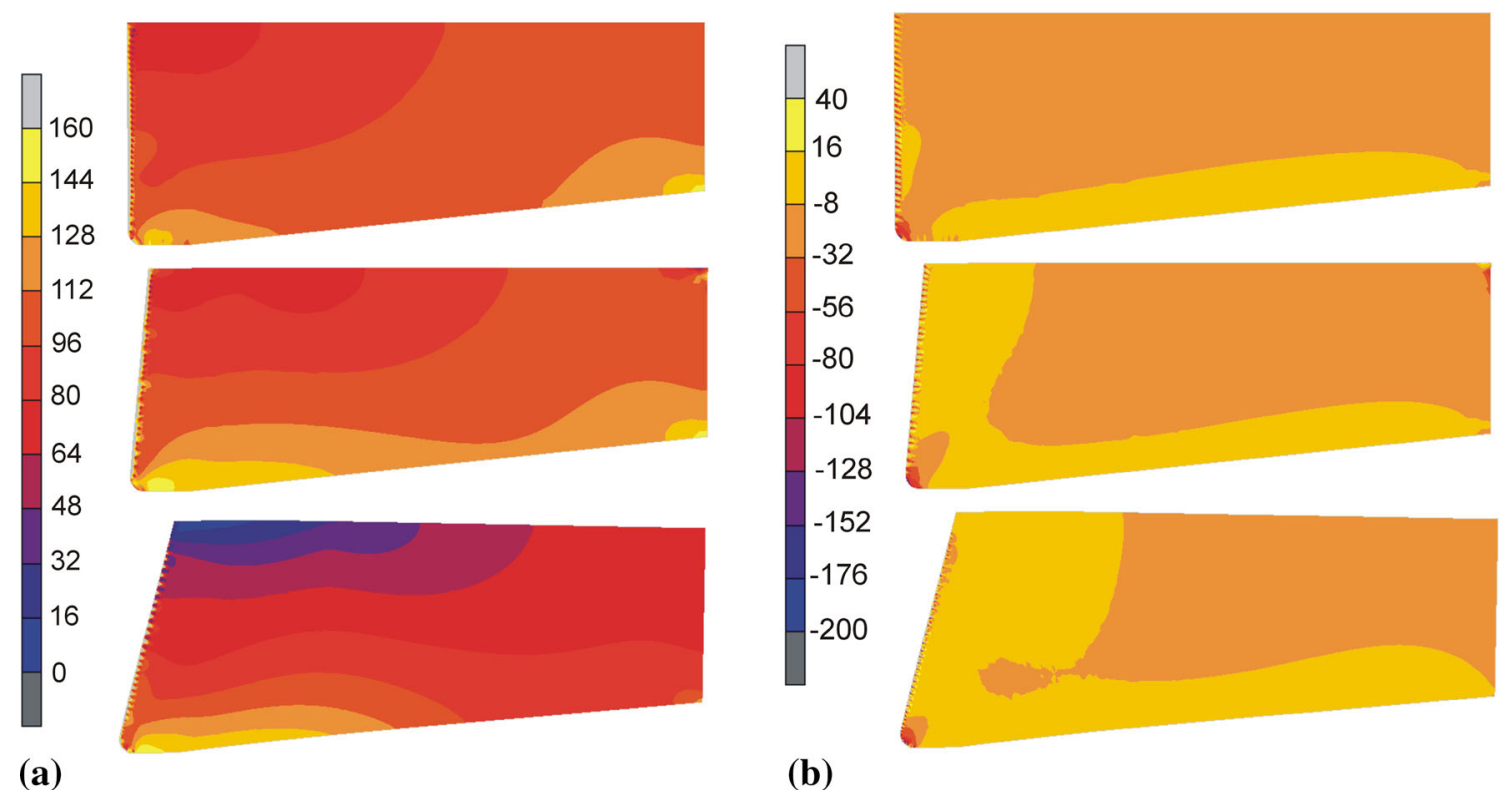

(a)

(b)

Fig. 5 Distribution of stress in dies during simulation of extrusion process: (a) effective stress and (b) radial stress

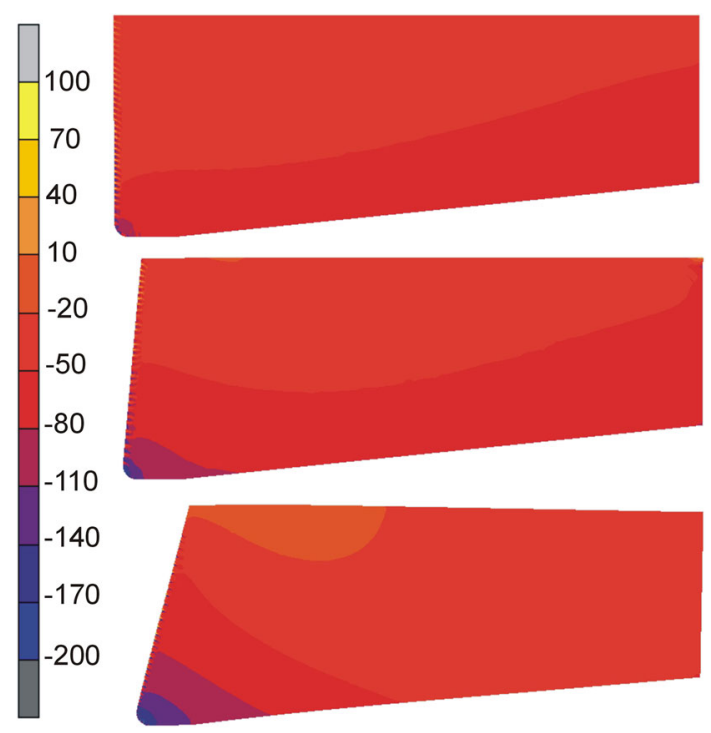

Fig. 6 The circumferential stress distribution in dies when simulating the extrusion process

improve the abrasion resistance. In general, the wear speed may be a function of the following process parameters: normal stress $\sigma_{\mathrm{n}}$ (perpendicular to the contact surface), relative slip speed of contacting bodies, temperature $T$, and hardness $H$, which is a function of temperature. The adhesive wear may be extracted from the equation proposed by Archard (Ref 1):

$\mathrm{d} V=k \frac{\mathrm{d} F \mathrm{~d} L}{H}$,

where $k$ is the wear coefficient, $\mathrm{d} V$ is the volume wear, $\mathrm{d} F$ is the normal force, $\mathrm{d} L$ is the friction path, and $H$ is the hardness.

In performed researches, the die wear profile during the extrusion was calculated by implementing Archard FEM-based wear model in MARC software as presented below:
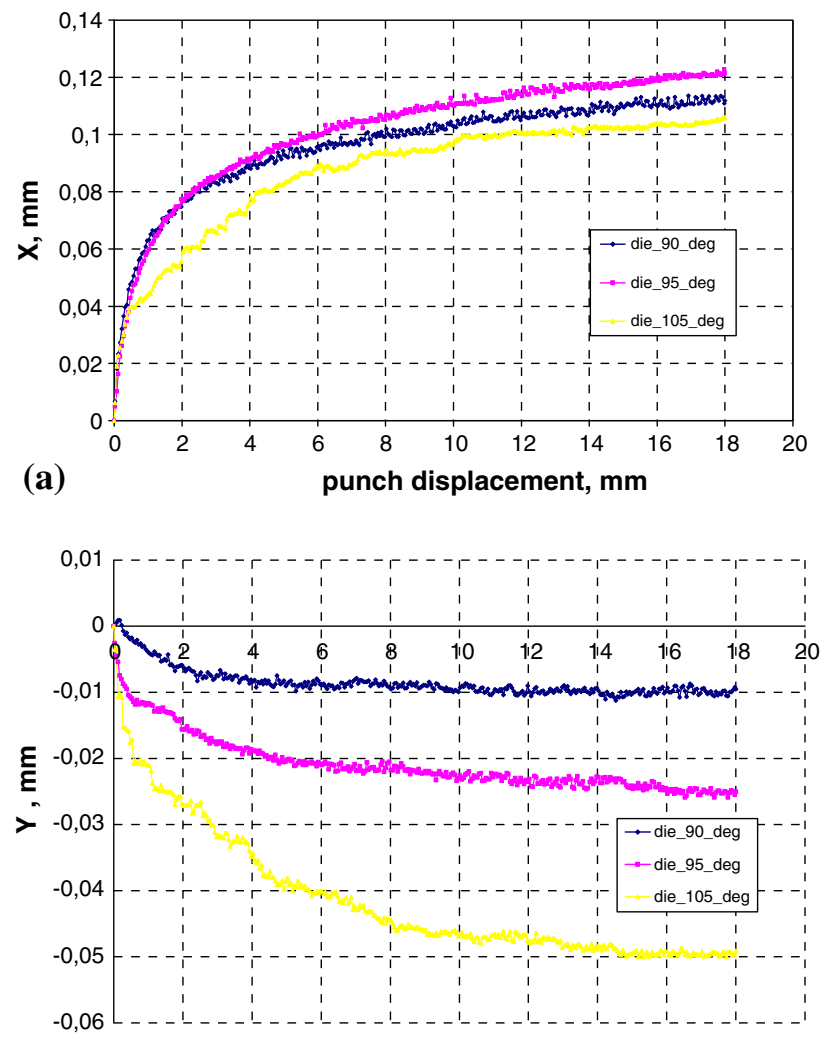

(b)

punch displacement, $\mathrm{mm}$

Fig. 7 The course of die displacement values in a direction: (a) $X$ axis and (b) $Y$ axis

$\stackrel{o}{w}=\frac{k}{H} \sigma_{\mathrm{n}} v_{\mathrm{rel}}$,

where $\stackrel{o}{w}$ is the wear speed, $\sigma_{\mathrm{n}}$ is the normal stress in contact, and $v_{\text {rel }}$ is the relative slip speed. 
The wear amount indicated as the wear coefficient was calculated using the equation as follows:

$w_{n+1}=w_{n}+\stackrel{o}{w} t$,

where $w_{n+1}$ is the current wear depth, $w_{n}$ is the wear amount in the previous computation step, $w$ is the wear speed, and $\Delta t$ is the time in the computation step.

The tool wear index may be a criterion to evaluate the tool durability, and in analyzed case used in the comparative analysis of effect of the die angle on the wearing speed. In performed researches, the wear coefficient $k$ equaled $10^{-4}(\operatorname{Ref} 2)$.

In order to specify the effect of die geometry on the tool wear, several 10 measurements of calculated wear depth were taken for individual examined dies. The measurements were performed for all dies in 22 measurement points as presented on Fig. 8.

The zones of the most intensive tool wear were expressed as the wear index (Eq 4), which corresponds to the wear depth due to a material displacement on the tool surface. The wear index distributions and its values in the most intensive wear for individual tools were presented on Fig. 9. The highest wear index values were observed near the die rounding radius. In turn, more intensive die wear in this area negatively affects the

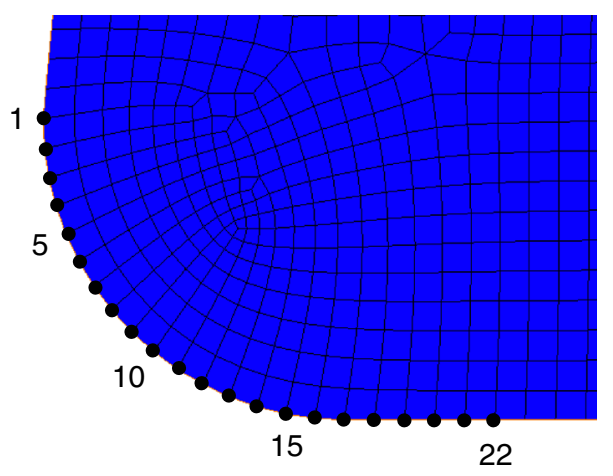

Fig. 8 Region and measuring points of wear depth in all models dimensional accuracy and deterioration of extruded material surface quality.

Maximum calculated values of die wear index in the critical areas are as follows:

- Die $90^{\circ}: W=5.62 \times 10^{-4} \mathrm{~mm}$

- Die $95^{\circ}: W=7.09 \times 10^{-4} \mathrm{~mm}$

- Die $105^{\circ}: W=4.95 \times 10^{-4} \mathrm{~mm}$

Calculated wear depths for dies of various angles were presented on Fig. 10. The highest local tool wear was found in the results for the die with cone angle $95^{\circ}$. The results indicate that the wear amount depends on the die used (die angle) and that the wear accumulates along the internal die surface, with its maximum value at the entry to the die hole. Note also that the maximum value is achieved in a different way, depending on the die geometry. The most advanced maximum wear value was noted for the die with angle $90^{\circ}$ in measurement point 11, and the most retarded maximum wear value for the die with angle $105^{\circ}$ in measurement point 13 . This is due to a higher load of the flat die surface in this area comparing to other cases. Numerically calculated position of the most intensive wear areas are related to the flow direction change with simultaneous high deformation intensity gradient.

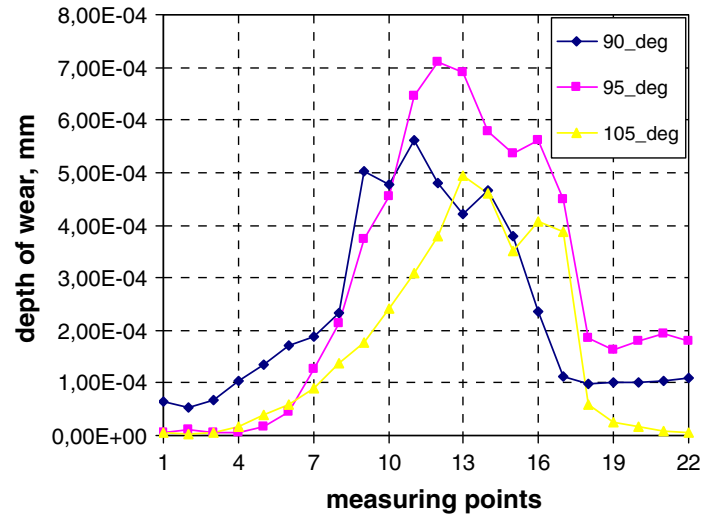

Fig. 10 Wear depth in particular areas of die corners
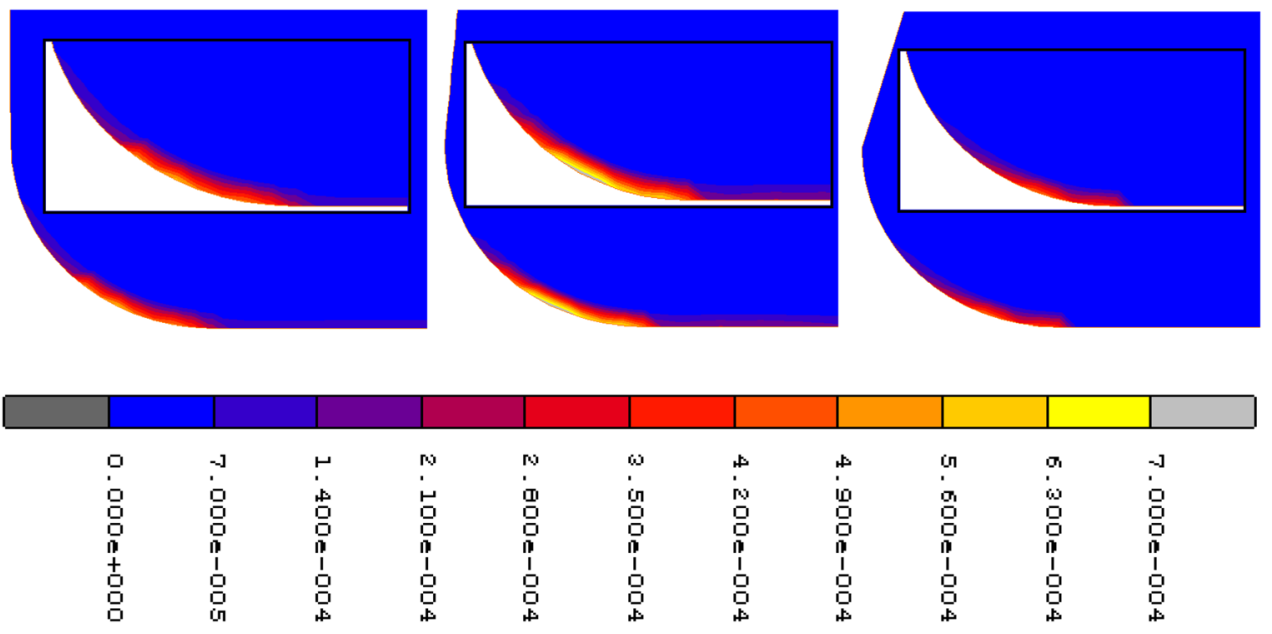

Fig. $9 W$ index distribution $w, \mathrm{~mm}$ of tools and the area of the most intensive wear: (a) die $90^{\circ}$, (b) die $95^{\circ}$, and (c) die $105^{\circ}$ 


\section{Conclusions}

This article presents the comparative research of load and wear of die at various angles of working cone during the concurrent extrusion. Performed researches allowed to determine the stress distribution and apex displacement for dies of various geometries. When using the flat die, the most loaded part of a die is the one near the calibrating strip and the lower part. In turn, the convex die specific radial stress revealed may indicate a different metal flow by the die comparing to the flat die. When analyzing the peripheral stress distribution, the highest stress values exist for the convex die with the working cone angle of $105^{\circ}$.

Archard model was used to determine the die wear. This model was implemented in the software using the FEM. The theoretical areas of the most intensive die wear were determined depending on the die working cone angle. The highest wear was noted for the die with angle $95^{\circ}$. It was validated that properly shaped die has an effect not only on the extruded material properties, but also controls the tool load. Performed researches including the die wear analysis and stress concentration may be helpful on the die designing stage, as this provides with important data affecting the die damage. Moreover, such an approach allows to determine the expected tool durability right in the tool design stage.

\section{Open Access}

This article is distributed under the terms of the Creative Commons Attribution License which permits any use, distribution, and reproduction in any medium, provided the original author(s) and the source are credited.

\section{References}

1. G. Giuliano, Process Design of the Cold Extrusion of Billet Using Finite Element Method, Mater. Des., 2007, 28, p 726-729

2. G.A. Lee and Y.T. Im, Finite Element Investigation of the Wear and Elastic Deformation of Dies in Metal Forming, J. Mater. Process. Technol., 1999, 89-90, p 123-127
3. I.V. Kragelsky, M.N. Dobychin, and V.S. Mombalov, Friction and Wear Calculation Methods, Pergamon Press, New York, USA, 1982

4. J.F. Archard, Contact and Rubbing of Flat Surfaces, J. Appl. Phys., 1953, 24, p 981-988

5. H.I. Demirci and H. Evlen, Effect of Extrusion Ratio on the Wear Behaviour of Al-Si and Al-Mg Alloys, J. Alloy Compd., 2012, 510, p 26-32

6. Ch Choi, A. Groseclose, and T. Altan, Estimation of Plastic Deformation and Abrasive Wear in Warm Forging Dies, J. Mater. Process. Technol., 2012, 212, p 1742-1752

7. T. Sobis, U. Engel, and M. Geiger, A Theoretical Study on Wear Simulation in Metal Forming Process, J. Mater. Process. Technol., 1992, 34(1-4), p 233-240

8. Y. Tronel and Y.L. Chenot, Prediction of Tool Wear Using FiniteElement Software for the 3-Dimensional Simulation of the Hot-Forging Process, J. Mater. Process. Technol., 1992, 31(1), p 255-263

9. S. Stancu-Niederkorn, U. Engel, and M. Geiger, Ultrasonic Investigation of Friction Mechanism in Metal-Forming, J. Mater. Process. Technol., 1994, 45(1-4), p 613-618

10. B. Painter, R. Shivpuri, and T. Altan, Prediction of Die Wear During Hot-Extrusion of Engine Valves, J. Mater. Process. Technol., 1996, 59, p 132-143

11. B.A. Behrens, Finite Element Analysis of Die Wear in Hot Forging Processes, CIRP Ann. Manuf. Technol., 2008, 57, p 305-308

12. J.H. Kang, I.W. Park, J.S. Jae, and S.S. Kang, A Study on a Die Wear Model Considering Thermal Softening (I): Construction of the Wear Model, J. Mater. Process. Technol., 1999, 96, p 53-58

13. J.H. Kang, I.W. Park, J.S. Jae, and S.S. Kang, A Study on a Die Wear Model Considering Thermal Softening (II): Application of the Suggested Wear Model, J. Mater. Process. Technol., 1999, 94, p $183-188$

14. T. Iwama and Y. Morimoto, Die Life and Lubrication in Warm Forging, J. Mater. Process. Technol., 1997, 71, p 43-48

15. S. Kut and I. Nowotynska, Comparative Numerical Analysis of Die Wear During Extrusion Process of Metals With Different Properties, Hutnik, 2011, 11, p 925-930 (in Polish)

16. T. Altan and M. Knoerr, Application of the 2D Finite Element Method to Simulation of Cold-Forging Processes, J. Mater. Process. Technol., 1992, 35(3-4), p 275-302

17. R. Dragutinowic, J. Zasadziński, Flow of Aluminum Alloys During Extrusion Through the Dies of Various Geometry, Proceedings of the Sixth International Symposium on Plasticity and Resistance to Metal Deformation, Herceg-Novi, 1989, p 107-110

18. I. Nowotynska and A. Smykla, Influence of Die Geometric Parameters on Plastic Flow of Layer Composites During Extrusion Process, J. Mater. Process. Technol., 2009, 209, p 1943-1949

19. W. Libura, J. Zasadzinski W.Z. Misiolek, Metal Flow Control in Extrusion, International Congress on Metallurgy and Materials Technology, Sao Paulo, Brasilia, t.6, 1994, p 231-238

20. MSC Software: MSC. Marc Volume B: Element Library, Version 2010 